\title{
Monitoring survey of caffeine in surface waters (Lis River) and wastewaters located at Leiria Town in Portugal
}

\author{
Paula Paíga $^{1} \cdot$ Sandra Ramos ${ }^{2} \cdot$ Sandra Jorge $^{3} \cdot$ Jaime Gabriel Silva $^{4,5} \cdot$ Cristina Delerue-Matos $^{1}$
}

\begin{abstract}
Investigation during 11-month period was performed to study the presence of caffeine in the Lis River in Leiria Town in Portugal, and a monitoring during 9-month period was realized to check the contribution of the human pollution of two wastewater treatment plants (WWTPs) that discharge their effluents to the studied river. The samples were collected in five sampling points along the river and in two influents and two effluents of the studied WWTPs. Caffeine was detected in all ninety-one collected samples. The caffeine concentration ranged from 25.3 to $321 \mathrm{ng} / \mathrm{L}$ in the river samples, from 112 to $1927 \mathrm{ng} / \mathrm{L}$ in the WWTP effluents, and from 9478 to $83,901 \mathrm{ng} / \mathrm{L}$ in the WWTP influents. The highest concentration in the river was detected in the two sampling points located after the effluent discharge points and reached 315 and $321 \mathrm{ng} / \mathrm{L}$. Risk assessment was performed for three trophic levels using the risk quotient calculation and revealed that caffeine do not cause toxic effect on Daphnia magna and on fish but could be possibly toxic to algae. The results proved that caffeine can be an effective indicator of human-born pollution.
\end{abstract}

Keywords Caffeine $\cdot$ Liquid chromatography $\cdot$ Mass spectrometry $\cdot$ Monitoring study $\cdot$ Risk assessment

\section{Introduction}

Millions of people all around the world consume daily products containing caffeine. This compound can be commonly found in food and many beverages such as coffee, chocolate, tea, soft drinks, cakes, and cookies (Edwards et al. 2015;

Cristina Delerue-Matos cmm@isep.ipp.pt

REQUIMTE/LAQV, Instituto Superior de Engenharia do Porto, Politécnico do Porto, Rua Dr. António Bernardino de Almeida, 431, 4200-072 Porto, Portugal

2 CEAUL, Universidade de Lisboa, Portugal and LEMA, Instituto Superior de Engenharia do Porto, Instituto Politécnico do Porto, Rua Dr. António Bernardino de Almeida, 431, 4200-072 Porto, Portugal

3 Águas do Centro Litoral, SA, Grupo Águas de Portugal, ETA da Boavista, Avenida Dr. Luís Albuquerque, 3030-410 Coimbra, Portugal

4 Águas de Santo André, Cerca da Água, Rua dos Cravos, 7500-130 Vila Nova de Santo André, Portugal

5 Departamento de Engenharia Civil, Instituto Superior de Engenharia do Porto, Instituto Politécnico do Porto, Porto, Portugal
Peteffi et al. 2018) as well as in some medications like pain relievers, diet pills, and anti-cold and anti-allergy pharmaceuticals (Mahoney et al. 2019). The main caffeine pollution sources are disposal of unconsumed caffeine-containing beverages, and activities such as washing of dirty coffee cups (Seiler et al. 1999). Direct consumption does not contribute much as the human body can metabolize caffeine quite efficiently and only up to $10 \%$ is excreted unchangeably in urine (Ferreira 2005). The elimination of caffeine in wastewater treatment plants (WWTPs) strongly depends on the treatment methods (Benotti and Brownawell 2007; Boisvert et al. 2012; Buerge et al. 2003; Siegener and Chen 2002; Yang et al. 2017) and can get below $10 \%$ using primary treatment (Boisvert et al. 2012).

Anthropogenic chemical markers have received a considerable attention in recent years as potential alternatives to identify pollution sources correlated with human activities (Kurissery et al. 2012). The quality of water can be assessed by microbiological tests (Escherichia coli); however, these are time-consuming and cannot indicate the origin of the contaminants (Hillebrand et al. 2012). Caffeine has a big potential in this field. In a study conducted in 40 sampling sites across the USA, 110 human-specific chemicals were evaluated and 
caffeine, carbamazepine, and diphenhydramine were used as human fecal indicators (Glassmeyer et al. 2005). Caffeine was also used as a domestic sewage indicator in Asahikawa River Basin, Japan (Kiguchi et al. 2016).

The European Union adopted a "Watch List" of potential priority substances including pesticides, pharmaceuticals, and personal care products. Monitoring studies are important to confirm the pollution, identify its main sources, estimate the contamination levels, and review the priority substances in the "Watch List." Such activities should be applied especially in river monitoring as they are the main water supplies for domestic uses, for many industry types, and for irrigation in agriculture. It is then essential to prevent and control their pollution to maintain good water quality and safety.

The first objective of the conducted study was to assess the magnitude of human pollution in the Lis River that has been subjected to continuous pollution by the effluents discharged from WWTPs and by illegal discharges of untreated wastewaters (Vieira et al. 2012). The second objective was to correlate the contamination levels with the weather influence (precipitation), the WWTP localizations, and the effluent and influent loadings; and assess the removal efficiency. The third objective was to evaluate toxicological effect on aquatic organisms on three trophic levels (Daphnia magna, algae, and fish). The aims were achieved by monitoring caffeine concentration in several points along the river course and in two WWTPs.

\section{Materials and methods}

\section{Site description}

Leiria is a city and a municipality in the Centro Region of Portugal (Fig. 1). It is crossed by $39.5 \mathrm{~km}$ long Lis River (Vieira et al. 2012). The river is an important inland water resource for domestic, industrial, and irrigation purposes in the region (LeiriaMunicipality n.d.). For this reason, it is important to prevent and control its water pollution (Akcay et al. 2003). Continuous illegal discharges of wastewater are still un unfinished chapter in the Lis River history, and many diffuse sources keep polluting water lines, contaminating water resources, and destroying biodiversity.

Grab samples were collected each month along the Lis River in five sampling points (SP1-5); composite samples collected with the same frequency were obtained by mixing grab samples taken every hour during $24 \mathrm{~h}$ from the wastewaters (effluent $\mathrm{E}$ and influent I) of two wastewater treatment plants (WWTP-A and WWTP-B) (Fig. 1). The river samples were collected on the same riverbank side if the water level allowed, and therefore, samples were collected a little further into the river. The sampling points SP3 and SP5 were located approximately $500 \mathrm{~m}$ downstream from the effluent discharged points of each station. The WWTP-A was located closer to the Lis River source while the WWTP-B was closer to the river mouth. The distance between the river mouth and the WWTP-A was $25 \mathrm{~km}$ and $5 \mathrm{~km}$ separated it from the WWTP-B.

The WWTP-A had been receiving mostly domestic wastes and the WWTP-B mainly domestic and hospital wastes together with animal farming sewage and landfill leachate. The average flow rate and the served population that the WWTP-B was designed to operate with were $37,997 \mathrm{~m}^{3} /$ day and 248,685 people. The conditions were harder than in the case of the WWTP-A that was meant to deal with $6250 \mathrm{~m}^{3} /$ day and 49,351 people. In 2014, the served population was 21,726 for the WWTP-A and 110,131 for the WWTP-B. The hydraulic retention time and the sludge retention time were $12.5 \mathrm{~h}$ and 16.4 days for WWTP-A and $25 \mathrm{~h}$ and 18 days for WWTP-B, respectively.

Primary and secondary treatments are performed in both WWTPs. The primary treatment in the WWTP-A bases on harrowing and desanding and in the WWTP-B on harrowing, desanding, and degreasing. The secondary treatments in both WWTPs are conducted with conventional activated sludge: in two aeration tanks preceded by an anoxic reactor in the WWTP-A and in three biological reactors divided into two parts, one working in anaerobic and the other in aerobic conditions in the case of the WWTP-B.

Amber glass bottles pre-rinsed with ultrapure water were used for the sample collection. The samples were maintained under refrigeration $\left(4^{\circ} \mathrm{C}\right)$ during the transport and filtered through a $0.45-\mu \mathrm{m}$ nylon membrane (Fioroni Filters, Ingré, France) in the laboratory. Then, the samples were extracted using solid-phase extraction (SPE) methodology and analyzed by means of liquid chromatography with tandem mass spectrometry detection (UHPLC-MS/MS). The samples were preserved in $-20^{\circ} \mathrm{C}$ in case they were not extracted immediately.

\section{Reagents, solvents, and materials}

Caffeine and a certified reference material containing caffeine- ${ }^{13} \mathrm{C}_{3}$ solution $(1.0 \mathrm{mg} / \mathrm{mL}$ in methanol) were purchased from Sigma-Aldrich (Steinheim, Germany). Methanol LC-MS Ultra CHROMASOLV ${ }^{\circledR}$ and Propanol LC-MS were purchased from Sigma-Aldrich (Steinheim, Germany), acetonitrile LC-MS grade was supplied by Biosolve (Valkenswaard, Netherlands), and formic acid $98 \%$ PA-ACS and hydrochloric acid $37 \%$ were obtained from Carlo Erba (Rodano, Italy). A Simplicity 185 system (Millipore, Molsheim, France) was used to produce ultrapure water (resistivity of $18.2 \mathrm{M} \Omega \mathrm{cm}$ ).

The solvents used in UHPLC-MS/MS were filtered through a $0.22-\mu \mathrm{m}$ nylon membrane filter (Fioroni Filters, Ingré, France) using a vacuum pump (Dinko D-95, Barcelona, Spain) The eluents were degassed for $15 \mathrm{~min}$ in 

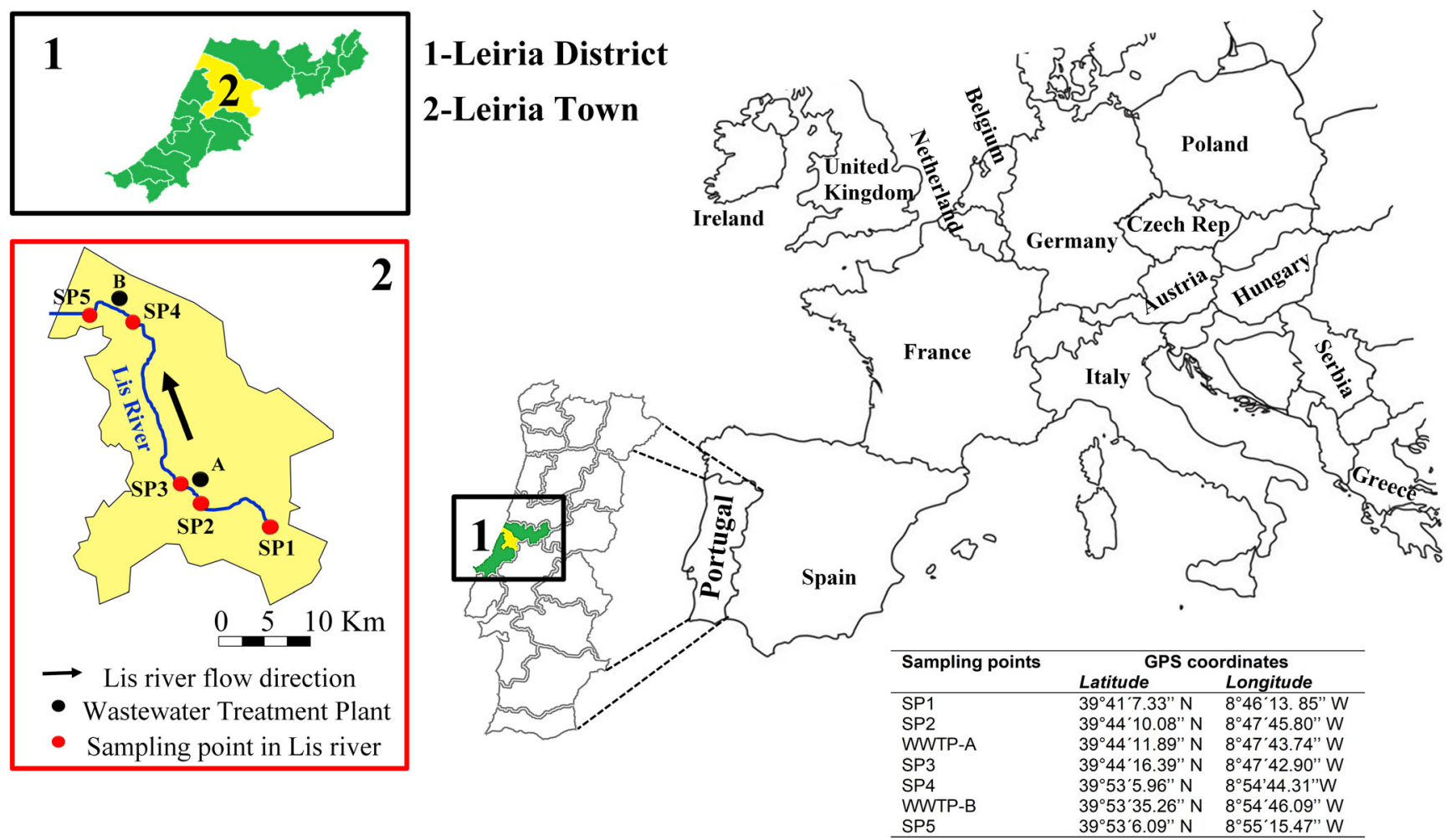

Fig. 1 Localization of the sampling points (SP) in the river and in the effluents and influents of the two WWTPs (source of the river (SP1) and before (SP2 and SP4) and after (SP3 and SP5) the discharge of the WWTPs)

an ultrasonic bath (Sonorex Digital 10P, Bandelin DK 255P, Germany).

Standard stock solutions of caffeine and caffeine- ${ }^{13} \mathrm{C}_{3}$ of $1 \mathrm{~g} / \mathrm{L}$ concentrations were prepared in methanol and stored in the dark at $-20^{\circ} \mathrm{C}$. Appropriate amounts of the caffeine stock solution were mixed with $10 \%$ of organic phase (acetonitrile) and $90 \%$ of aqueous phase $(0.1 \%$ formic acid in ultrapure water) to obtain the working standard solutions. In the recovery tests, samples of the three matrices (river, effluents, and influent) were spiked with working standard solutions and two spiking levels were performed.

Strata-X SPE cartridges ( $200 \mathrm{mg}, 3 \mathrm{~mL}$ ) from Phenomenex (CA, USA) were used in the SPE extraction. The sample extracts were filtered through $0.22-\mu \mathrm{m}$ PTFE syringe filters (Specanalitica, Carcavelos, Portugal) before the chromatographic analysis.

\section{Analytical method}

Samples with the $\mathrm{pH}$ adjusted 2 were pre-concentrated on Strata-X cartridges. The SPE cartridges were conditioned using the vacuum system manifold (Chromabond, Düren, Germany) first with $5 \mathrm{~mL}$ of methanol then with $5 \mathrm{~mL}$ of ultrapure water and finally $5 \mathrm{~mL}$ of ultrapure water of $\mathrm{pH} 2$. The $\mathrm{pH}$ adjustments of samples and ultrapure water were done using hydrochloric acid $37 \%$. In the next step, $250 \mathrm{~mL}$ of the river water, $100 \mathrm{~mL}$ of the WWTP effluents, and $50 \mathrm{~mL}$ of the
WWTP influents were passed through the SPE cartridges. The extraction was finished by passing $5 \mathrm{~mL}$ of ultrapure water through the cartridges that were then left to dry under vacuum for $60 \mathrm{~min}$. In the next step, methanol was used to extract the compound adsorbed in the cartridges. The extracts were evaporated with nitrogen at room temperature until dry and the residues dissolved in 10:90\% (v/v) acetonitrile- $0.1 \%$ formic acid in ultrapure water. Concentration factors of 500, 200, and 100 were obtained for the river samples, WWTP effluent samples, and WWTP influent samples, respectively (Paíga et al. 2017). At the end, $5 \mu \mathrm{L}$ of the caffeine $-{ }^{13} \mathrm{C}_{3}$ standard was added to the samples to obtain the final concentration of $200 \mu \mathrm{g} / \mathrm{L}$.

Chromatographic analysis was performed using a Shimadzu Nexera LCMS system (LCMS-8030, Kyoto, Japan) equipped with an autosampler (SIL-30AC), a degasser (DGU-30A3), a column oven (CTO-30A), and two solvent delivery modules (LC-30AD), and coupled to a triple-quadrupole MS detector with an electrospray ionization source (ESI). Argon was used as the collision gas at $230 \mathrm{kPa}$, and nitrogen was used for the nebulizer and as the drying gas.

Identification and quantification were performed using multiple reaction monitoring (MRM, precursor $>$ product ions). The MRM transitions and the MS parameters (Q1 prebias (V), Q3 pre-bias (V), and collision energy) were optimized automatically using the MRM optimization feature available in the LabSolutions software. Injections of the 
standard were performed and two highest signal transitions were recorded; the first on the most intensive was used for quantification and the second for identification.

The isotopically labeled internal caffeine $-{ }^{13} \mathrm{C}_{3}$ standard was used to compensate the matrix effect. Only one transition (the most intense) was recorded for caffeine- ${ }^{13} \mathrm{C}_{3}$. The obtained MS parameters are given below:

caffeine:

$195.05>138.20$ (Q1 pre-bias, $-10 \mathrm{~V}$; CE, $-22 \mathrm{eV}$; and Q3 pre-bias, $-14 \mathrm{~V}$, quantification ion); $195.05>42.15$ (Q1 prebias, $-10 \mathrm{~V}$; CE, $-37 \mathrm{eV}$; and Q3 pre-bias, $-15 \mathrm{~V}$, identification ion)

$$
\text { caffeine- }-{ }^{13} \mathrm{C}_{3} \text { : }
$$

$198.05>140.10(\mathrm{Q} 1$ pre-bias, $-10 \mathrm{~V}$; CE, $-21 \mathrm{eV}$; and Q3 pre-bias, $-27 \mathrm{~V}$ )

The LabSolutions software (version 5.80, Shimadzu) was used for data processing and system control. Caffeine and caffeine- ${ }^{13} \mathrm{C}_{3}$ were analyzed in positive ionization mode.

A standard $10 \mathrm{mg} / \mathrm{L}$ mixture solution was used for the source-dependent parameter optimization by direct injection. The optimized parameter values were as follows: interface voltage, $5.0 \mathrm{kV}$; nebulizer gas flow rate, $2.6 \mathrm{~L} / \mathrm{min}$; drying gas flow rate, $15 \mathrm{~L} / \mathrm{min}$; desolvation line temperature, $30{ }^{\circ} \mathrm{C}$; and heat block temperature, $425^{\circ} \mathrm{C}$.

A Cortecs ${ }^{\mathrm{TM}}$ UPLC $^{\circledR} \mathrm{C} 18+$ column $(100 \times 2.1 \mathrm{~mm}$ i.d.; $1.6 \mu \mathrm{m}$ particle size) from Waters (Milford, MA, USA) was used in the experiments. The mobile phase eluents were $0.1 \%$ formic acid in ultrapure water (eluent $\mathrm{A}$, aqueous phase) and acetonitrile (eluent $\mathrm{B}$, organic phase). The elution gradient started with $10 \%$ of the eluent $\mathrm{B}$, increased to $100 \%$ of the eluent $\mathrm{B}$ in $2 \mathrm{~min}$, maintained for $0.5 \mathrm{~min}$, and then returned to the initial conditions in $1 \mathrm{~min}$. The column was re-equilibrated for $2.5 \mathrm{~min}$ before the next injection. The retention times for caffeine and caffeine- ${ }^{13} \mathrm{C}_{3}$ were $2.184(\mathrm{RSD}=0.673 \%)$ and $2.182 \mathrm{~min}$ $(\mathrm{RSD}=0.0850 \%)$, respectively; the injection volume was $5 \mu \mathrm{L}$ and the flow rate was $0.3 \mathrm{~mL} / \mathrm{min}$, respectively. The autosampler temperature was $4{ }^{\circ} \mathrm{C}$ and the column temperature was $30^{\circ} \mathrm{C}$; the dwell time of $100 \mathrm{~ms}$ was used.

The identification and confirmation criteria for the caffeine analysis were based on the Commission Decision 2002/657/ EC (2002/657/EC 2002).

\section{Quality assurance and control}

The repeatability expressed as relative standard deviation (\%RSD), the recovery, matrix effects (ME), linearity, method detection limit (MDL, lowest analyte concentration with the $\mathrm{S} / \mathrm{N}$ ratio of 3 ), and method quantification limit (MQL, concentration with the $\mathrm{S} / \mathrm{N}$ ratio of 10 ) were evaluated, and the results are presented in "Caffeine quantification and the method validation." Injection of mobile phase (solvent blanks) was performed along the batch for the instrumental background monitoring. The MDLs and MQLs were determined using the whole chromatogram range.

\section{Statistical analysis}

All the statistical analysis was performed using the R software ( $\mathrm{R}$ Development Core Team 2016). The data is presented as mean \pm standard deviation or as median and range (min-max). The hypotheses of normal caffeine concentration distribution for several groups were rejected based on the KolmogorovSmirnov test. Consequently, differences between the groups were analyzed by non-parametric versions of the ANOVA test-the Kruskal-Wallis test for independent samples and by the Friedman test for matched samples. Post hoc tests for pairwise multiple comparisons were applied whenever significant differences were detected by the tests. The values $p \leq$ 0.050 were considered statistically significant.

\section{Risk quotient}

Risk quotient (RQ) was calculated at three different trophic levels of the ecosystem: algae, Daphnia magna, and fish based on data found in the literature and using ECOSAR software. According to the Technical Guidance Document of the European Commission, the RQ is calculated as the measured environmental concentration (MEC) divided by the predicted no-effect concentration $\left(\mathrm{PNEC}=\left(\mathrm{EC}_{50}\right.\right.$ or $\left.\left.\mathrm{LC}_{50}\right) / 1000\right)$ (Vazquez-Roig et al. 2012). To predict the highest negative effect of caffeine, the highest concentration of caffeine achieved in each type of samples was used. If the RQ is equal or greater than 1, there is a potential environmental risk (EMEA 2006; Thomaidi et al. 2015).

\section{Results and discussion}

\section{Caffeine quantification and the method validation}

Calibration curves, linearity, MDL, MQL, repeatability, recovery, and matrix effect were evaluated. The results and their discussion are presented in the following subsections.

\section{Calibration curves}

The calibration curves in solvent and in the sample's matrices (river water, WWTP influents, and WWTP effluents) were plotted in the range of 10 to $1000 \mu \mathrm{g} / \mathrm{L}$ to ensure that the concentrated samples would lie within the plotted curves. The curves were made for both transitions (precursor $>$ 
quantification product ions and precursor $>$ identification product ions) and were constructed using the ratio of the transition ion to isotopically labeled internal standard peak areas (area of the transition ion/area of the isotopically labeled internal standard) plotted against the caffeine ratio standard concentrations (concentration of the caffeine standard/concentration of the isotopically labeled internal standard). For both caffeine transitions, the calibration curves were linear with correlation coefficient $(\mathrm{R})$ greater than 0.999 . The quantification of the caffeine was performed by the internal standard approach.

\section{Method's detection and quantification limits}

MDLs and MQLs were determined using the river water and the WWTP effluent and influent samples. The obtained MDL and MQL values were 1.08 and $3.61 \mathrm{ng} / \mathrm{L}$ for the river water, 1.91 and $6.37 \mathrm{ng} / \mathrm{L}$ for the WWTP effluent, and 2.05 and $6.82 \mathrm{ng} / \mathrm{L}$ for the WWTP influent, respectively. Higher MDLs and MQLs were achieved in WWTP influent compared with the other matrices.

\section{Repeatability}

Three standards with concentrations of 100, 250, and $500 \mu \mathrm{g} /$ $\mathrm{L}$ were used for the repeatability analysis. One sequential and twelve standard injections were performed. The obtained RSD values were $4.31(100 \mu \mathrm{g} / \mathrm{L}), 3.57(250 \mu \mathrm{g} / \mathrm{L})$, and $1.94 \%$ $(500 \mu \mathrm{g} / \mathrm{L})$. In the next step, each standard was repeated in the beginning, during, and in the end of the batch sequence and the obtained RSD values were lower than $10 \%(8.51$ $(100 \mu \mathrm{g} / \mathrm{L}), 8.25(250 \mu \mathrm{g} / \mathrm{L})$, and $5.65 \%(500 \mu \mathrm{g} / \mathrm{L}))$. As expected, the highest RSD values were observed for the lowest concentrations and the lowest RSD values were achieved for the highest concentrations.

\section{Recoveries}

Recoveries were evaluated for all sample's types. The caffeine peak areas of the samples spiked prior to the SPE extraction (pre-spiked sample) and after the extraction (post-spiked sample) were compared (Paíga et al. 2017). Two spiking levels (0.2 (level I) and 0.5 (level II) $\mu \mathrm{g}_{\text {caffeine }} / \mathrm{L}_{\text {sample }}$ ) were performed. The results were:

- River water

Level I: $105 \%$ (RSD, $0.366 \%)$

Level II: $92.7 \%$ (RSD, $0.366 \%$ )

- WWTP effluent

Level I: $71.9 \%$ (RSD, 4.29\%)
Level II: $74.8 \%$ (RSD, 3.99\%)

- WWTP influent

Level I: $75.0 \%$ (RSD, 2.06\%)

Level II: $77.4 \%$ (RSD, $0.123 \%$ )

The results showed good precision of the developed method with the RSD lower than $4.5 \%$. The highest recoveries (between 93 and 105\%) were observed in the river samples, and all the remaining samples had similar recoveries ranging from 72 to $75 \%$.

\section{Matrix effect}

The slopes of the matrix-matched calibration curves for the three samples types were compared with the calibration curve slope prepared in the solvent (standards prepared with initial mobile phase conditions). The matrix effect (ME) higher than $100 \%$ indicates ionization enhancement and lower than $100 \%$ indicates suppression of the ionization (Panuwet et al. 2016). The results on the level of $17.9 \%$ for river water, $24.0 \%$ for WWTP effluent, and $37.4 \%$ for the WWTP influent showed ion suppression signals.

\section{Occurrence of caffeine in the Lis River and in the WWTP influents and effluents}

The caffeine concentration in all months and in all the sampling points is shown in Fig. 2. Caffeine was detected with the RSD values between 0.359 and $9.99 \%$ in all samples. The lowest caffeine concentration was found in the river water and the highest in the samples collected in the WWTP influents. The WWTP effluents have no influence on the samples collected at the SP1 and SP2 (Fig. 1) because these sampling points (SP) were upstream of the WWTP-A effluent discharge. The SP1 could be considered a control point because it is the furthest point from the first effluent discharge into the river course. Contrary to what would be expected, caffeine levels were higher in the SP2 than in the SP3 in January, February, April, May, and June of 2014. No discharge of the WWTP effluents was made from the SP3 to SP4 (Fig. 1). Therefore, the caffeine levels at the SP4 should be lower than at the SP3 due to dilution occurred in the course of the river. Nonetheless, higher values at the SP4 were observed in January, in April, in May, and in June of 2014 (Fig. 2). Located in a more urbanized area and at the end of the watercourse, SP5 was more susceptible to anthropogenic activities (Fig. 1). It was observed that the minimum caffeine concentration detected at the SP5 was higher than the minimum values found at the remaining SP. The results indicated that caffeine concentration in the SP5 was higher than in the SP4, except for November of 2013 and January and June of 2014 

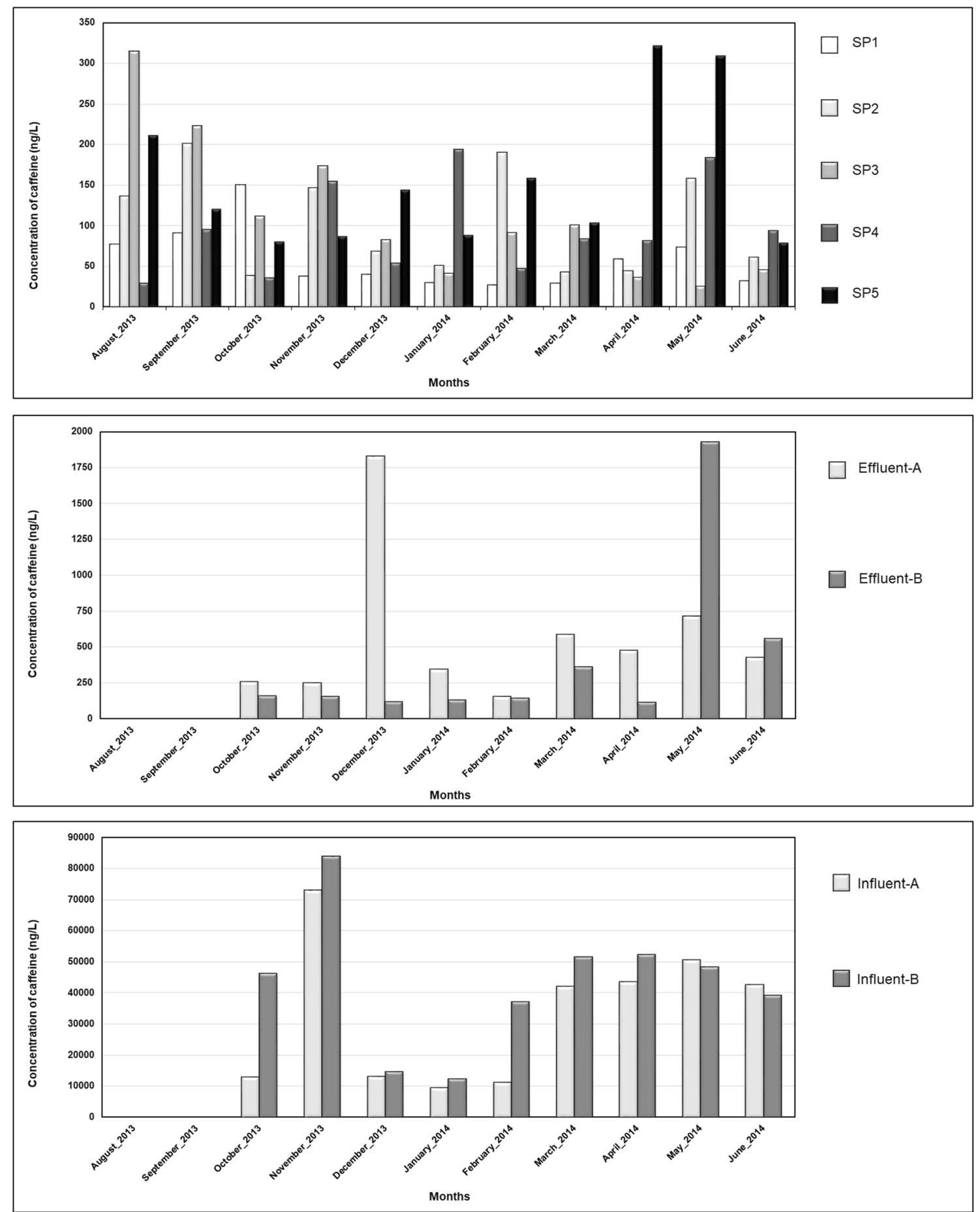

Fig. 2 Concentration of caffeine found at each sampling point in river waters and in WWTP effluent and influent samples (SP, sampling point in the river; E-WWTP, effluent; I-WWTP, influent)

(Fig. 2). The presence of caffeine in the SP1 and SP2 and the unexpected results obtained in the SP4 provide an evidence of the direct discharges of untreated sewage into the Lis River.

Seasonal changes are important in assessing temporal variations of river's pollution (Florescu et al. 2011). In 2015, Nannou et al. reported higher caffeine levels in the surface waters in spring and summer due to high beverage consumptions and lower caffeine levels in winter, owing to the dilution as a consequence of high rainfall (Nannou et al. 2015). Concerning the fact, the caffeine concentration in the river presented (Fig. 2) and the total precipitation data shown in Figure SM1 (Supplementary Material) were correlated and overlaid in the radar chart in Fig. 3 for a better comparison and discussion of the obtained results. Moreover, a map showing 


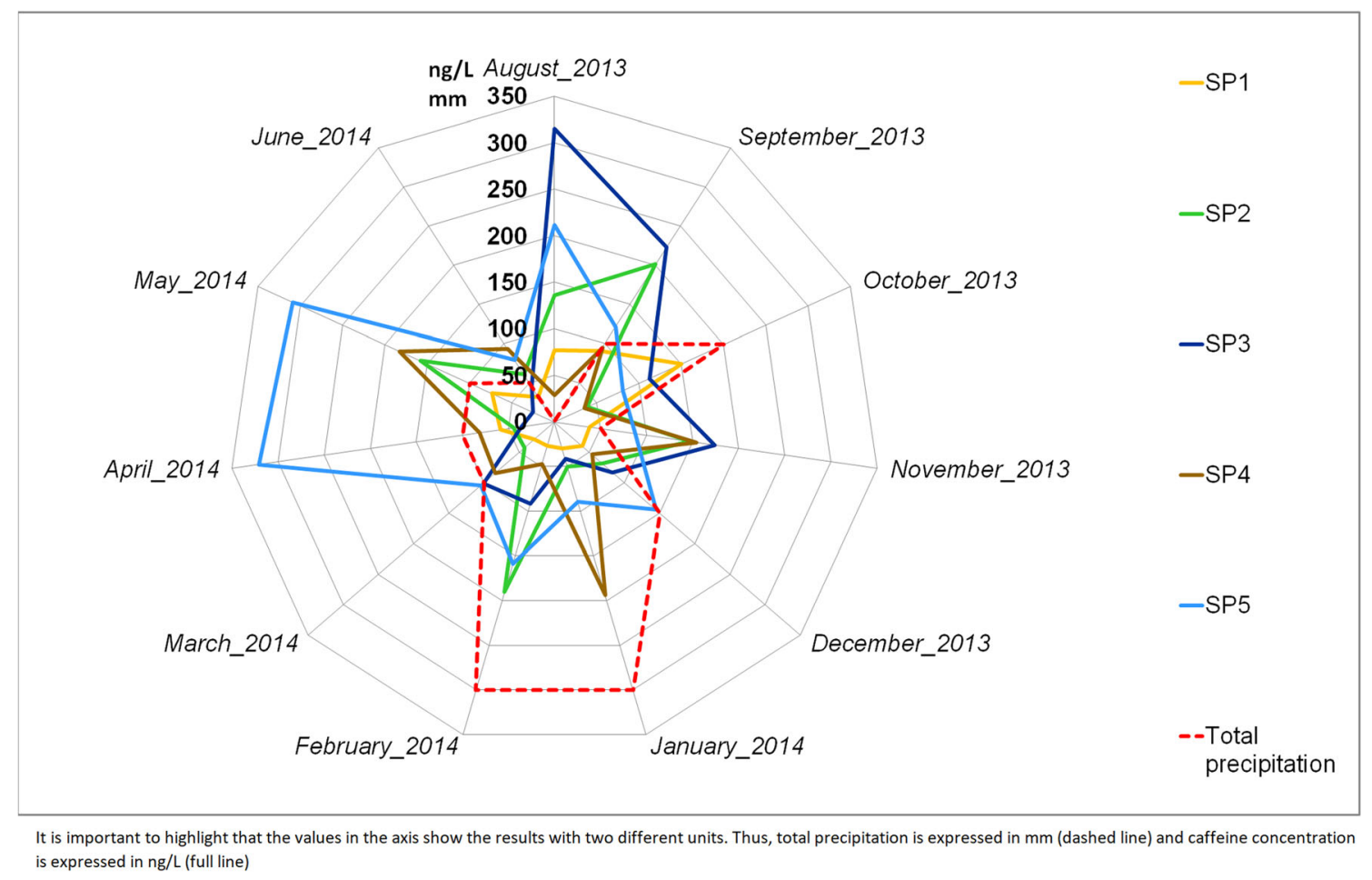

Fig. 3 Total precipitation ( $\mathrm{mm}$ ) and caffeine concentration (ng/L) versus months

the total precipitation in the studied region from August of 2013 to July of 2014 , based on data provided by the Portuguese Institute of the Sea and the Atmosphere, is presented in Figure SM1 in the Supplementary Material.

Another important variable is the effluent load to the study river. The effluent loadings (Figs. 4 and 5) were calculated as described in the work of Paíga et al. (2016). Thus, the increase and decrease of the total precipitation, effluent loading, and caffeine levels were summarized in Table SM1 in the Supplementary Material. The results were compared and discussed for each month. It was found out that in August of 2013, the caffeine level was the highest and the precipitation level was the lowest; in January and February of 2014 were the months with the highest rainfall. Detailed information is given in the following subsections for each sample type.

\section{River samples}

Within the 55 river samples, in $94.5 \%$ of them, the caffeine concentrations are below $300 \mathrm{ng} / \mathrm{L}$ and in $5.5 \%$, between > 300 and $<350 \mathrm{ng} / \mathrm{L}$. The highest caffeine concentration was found in the samples collected in the SP3 $(315 \mathrm{ng} / \mathrm{L})$ and the SP5 (321 ng/L).
Fig. 4 Loading (mg/day/1000 inhabitants) of the two WWTPs of influents' samples

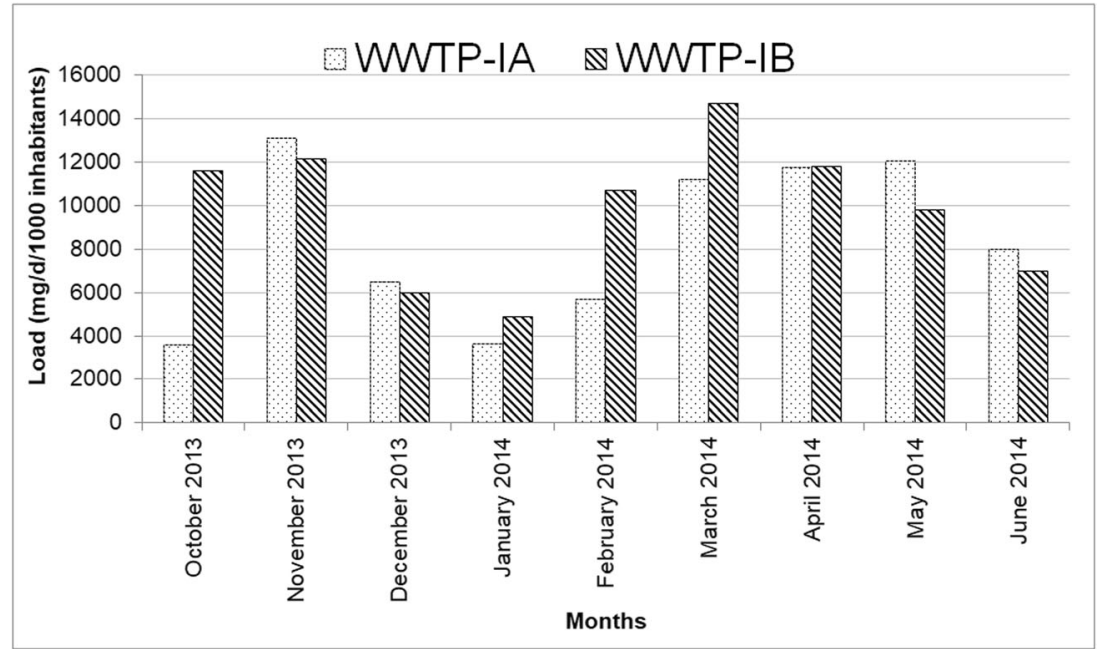


Fig. 5 Loading (mg/day/1000 inhabitants) of the two WWTPs of the effluents' samples

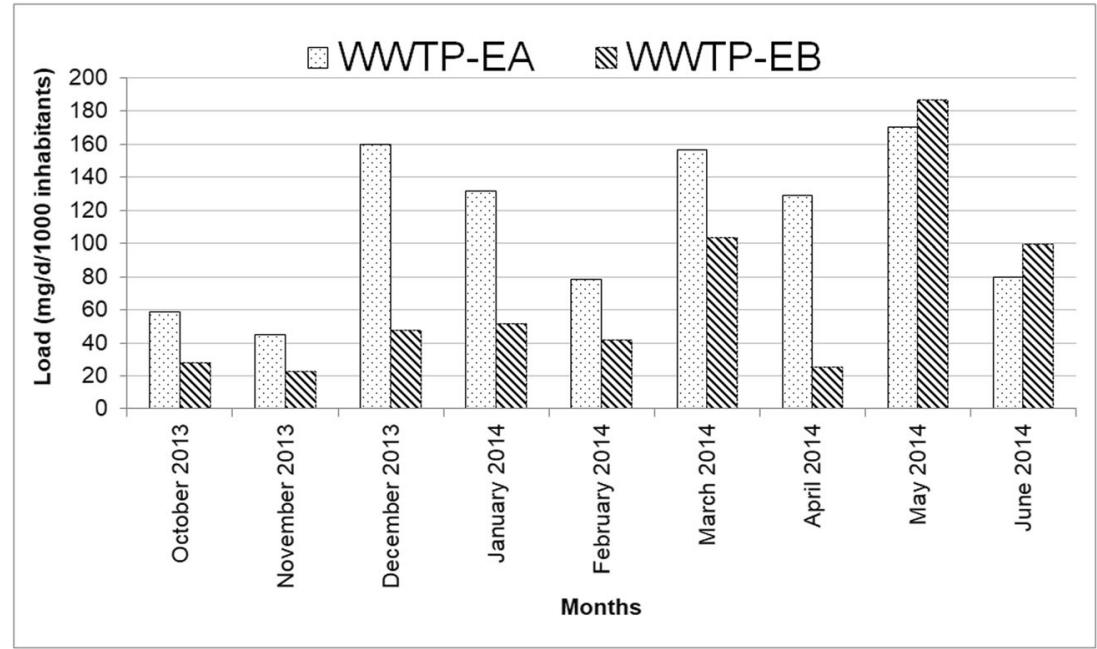

The caffeine levels varied with seasonal changes and with variation of the effluent loadings (Figs. 3 and 5 and Table SM 1 (Supplementary Material)). However, some exceptions were observed and may be associated with discharges of untreated wastewater into the river or lower caffeine consumption by the population. To improve the river water quality, the unknown contamination sources should be identified by the authorities and some preventive action must take to stop the pollution discharges.

Despite the differences observed in each sampling point, a Kruskal-Wallis test revealed that the caffeine concentration levels do not vary significantly between months based on the river sample analysis $\left(\chi^{2}(10)=8.6026, p>0.050\right)$ (Fig. 6). Although higher values of caffeine concentrations have been observed, in median terms, as the sampling points move away from the river beginning, a post hoc Wilcoxon rank-sum tests with Bonferroni's correction showed only significant differences between the sampling points SP1 and SP5 ( $p=0.007)$ (Fig. 7).

\section{Wastewater samples}

In the WWTP influents, the caffeine concentration was in the range of micrograms per liter; in the case of the effluents, only $11.1 \%$ of the samples exhibited caffeine concentration in such range. The months with the lowest loadings in the WWTP influents (Fig. 4) were October of 2013 for the WWTP-A and January of 2014 for the WWTP-B. The highest loads were observed in November of 2013 for the WWTP-A and in March of 2014 for the WWTP-B. The most significant difference between the two stations was recorded in October of 2013 and February of 2014 when the loads in the WWTP-B were significantly higher (Fig. 4). October and February were

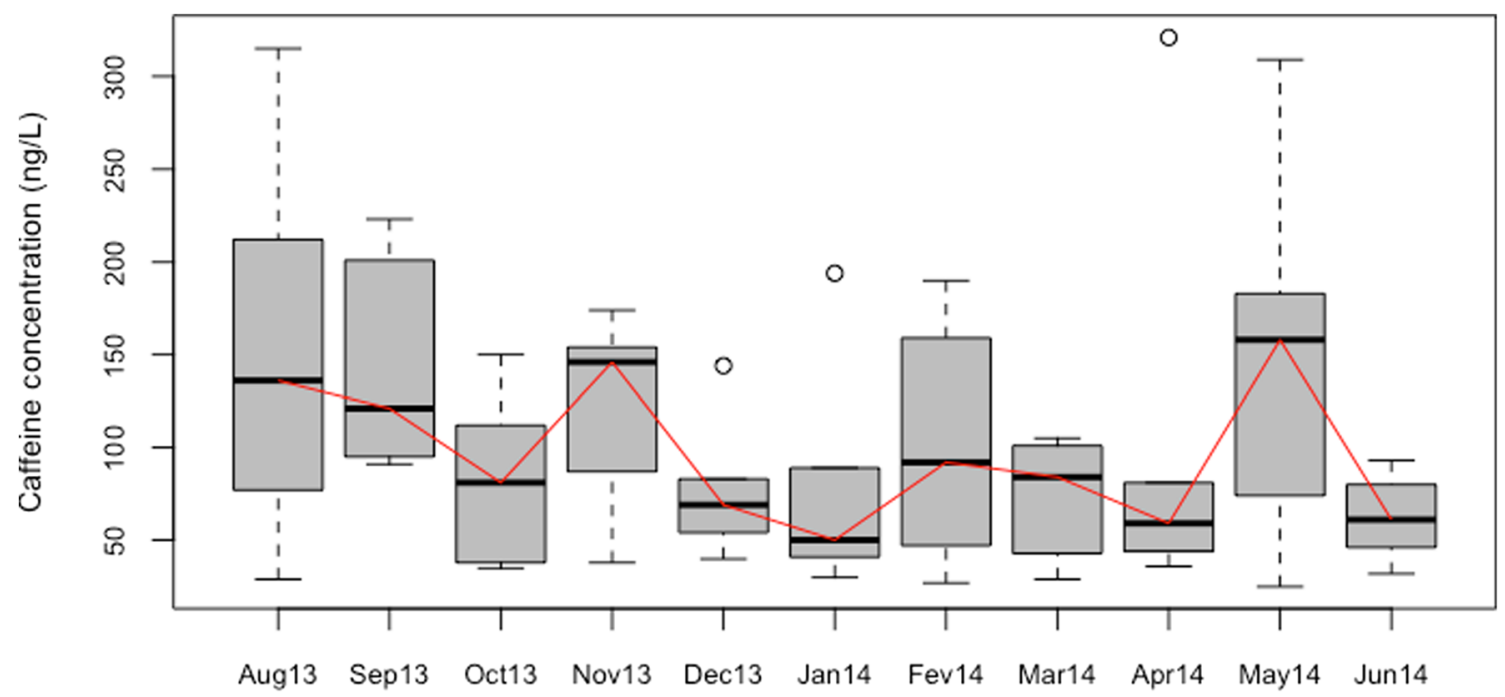

Months

Fig. 6 Distribution of caffeine concentration (ng/L) by sample collection month between August of 2013 to June of 2014 


\section{a Parallel coordinates plot}

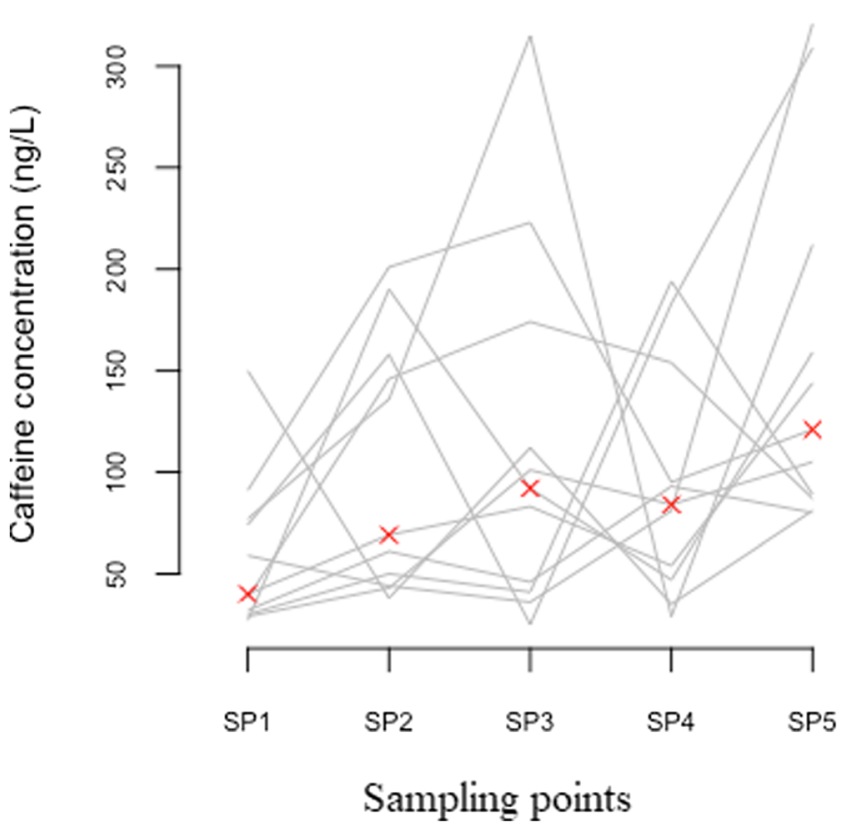

Fig. 7 Parallel coordinates of caffeine concentration (ng/L) for river sampling points (a) and boxplot of the differences between caffeine concentrations observed in any two river sampling points (b). The red

two of the studied months with the highest total precipitation values what might have enhanced the consumption of caffeinated hot beverages.

The investigated WWTPs were effective in caffeine removal of with efficiencies ranging from 96.4 to $99.8 \%$. The removal efficiency for each month was calculated according to the equation used in the work of Paíga et al. (2016); the values are shown in Figure SM2 in the Supplementary Material. The results are in accordance with previous studies of Heberer (2002) and Stamatis and Konstantinou (2013).

Comparing the removal efficiency in the studied WWTPs, it can be seen that the highest values were in the WWTP-B except for May and June. The results of the loadings (Fig. 4, influent; Fig. 5) are well correlated with the removal efficiencies (Figure SM2 in the Supplementary Material). For example, comparing the results in May and June for both WWTP, it could be observed that WWTP-A had a higher influent loading, but also had a higher removal efficiency consequently giving a lower effluent loading. Moreover, the most pronounced difference between the effluent loadings of these treatment plants was observed in December, January, and April. Moreover, December and January showed the lowest removal efficiency values in the WWTP-A. The results obtained in the effluent loadings were influenced by the removal efficiency values.

In both WWTPs, higher caffeine concentration values were observed in the influent samples, while the effluent and river samples presented closer values. The inferential statistics b Boxplots (of the differences)

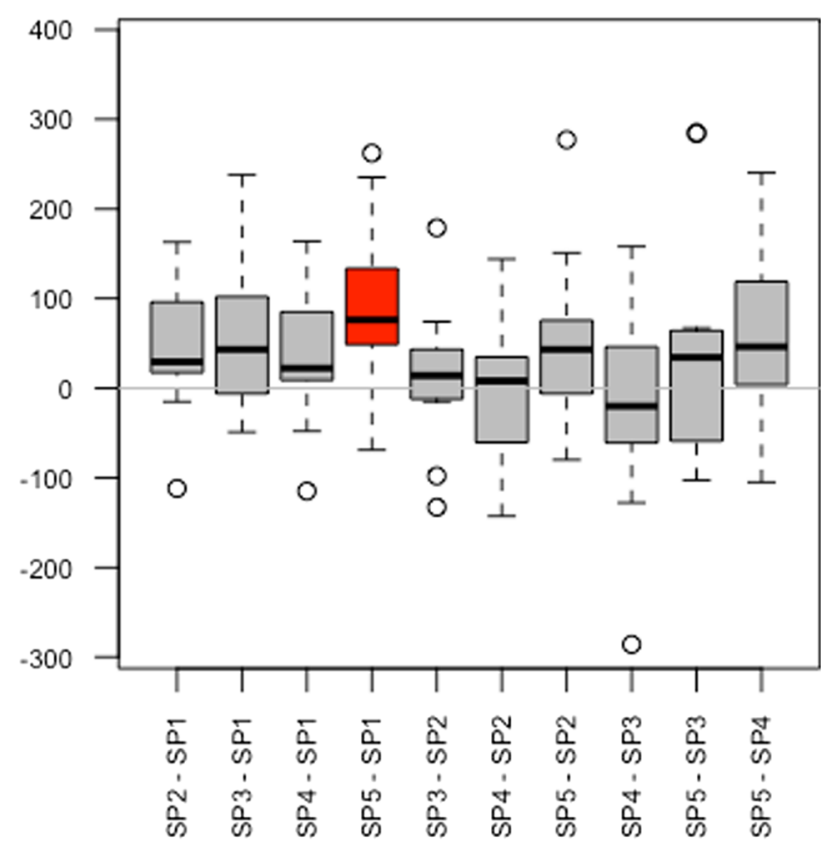

cross represents the median of caffeine concentration in each sampling point and the red box points out the significant difference amongst the two groups

showed that there was a significant difference between the three sampling points in both WWTPs $(p<0.001$ for WWTP-A and $p=0.001$ for WWTP-B). For the WWTP-A, a post hoc analysis showed that the difference was due to discrepancies between the influent and the effluent sampling points $(p=0.008)$ as well as between influent sampling point and the SP3 point $(p<0.001)$. For the WWTP-B, the difference was caused as well by divergence between the influent and effluent sampling points $(p=0.013)$ and differences between the influent sampling point and the SP5 point ( $p=$ 0.001) (Figs. 6 and 7).

\section{Literature data of caffeine concentrations in river water and WWTP wastewaters}

Some examples of the caffeine concentration found in literature in river water and in WWTP influents and effluents are presented in Table SM2 (Supplementary Material). Caffeine concentrations based on a literature review may vary from 0.600 (Loos et al. 2007) to $357,000 \mathrm{ng} / \mathrm{L}$ (Ferreira 2005) in rivers, from 23.0 (Kim and Carlson 2007) to $43.500 \mathrm{ng} / \mathrm{L}$ (Huerta-Fontela et al. 2008) in effluents, and from 440 (Martín et al. 2012) to $209,000 \mathrm{ng} / \mathrm{L}$ (Huerta-Fontela et al. 2008) in WWTP influents. One of the highest caffeine concentrations in river on the level of $357,000 \mathrm{ng} / \mathrm{L}$ was found in Brazil. The authors reported that these results clearly demonstrated areas with water quality problems (Ferreira 2005). The 
results in our study are in accordance with the studies mentioned in Table SM2 (Supplementary material).

\section{Risk quotient}

To predict the environmental hazards of caffeine, the highest concentration of caffeine in each sample type was measured and the risk quotient (RQ) determined. The maximum caffeine concentration levels found in this study for neither pose a toxic effect for fish and Daphnia magna but can have possible adverse effects on algae. Based on the information obtained in the work of Fernández et al. (2010) and in ECOSAR program (ECOSAR n.d.), algae are amongst the most sensitive specie due to the lowest value of $\mathrm{EC}_{50} / \mathrm{LC}_{50}$ (Table SM3, Supplementary Material).

\section{Conclusion}

Caffeine was detected in all 91 samples collected from a river and wastewaters from two water treatment plants (WWTP-A and WWTP-B) localized in the Leiria Region in central Portugal. The caffeine concentrations ranged from $25.3 \mathrm{ng} / \mathrm{L}$ in the river water to $83,901 \mathrm{ng} / \mathrm{L}$ in the WWTP-B influent. The calculated risk quotient indicated no adverse effect on fish and Daphnia magna but possible adverse effects on algae. The removal efficiencies of the two treatment plants were high on average level of $98.4 \%$ for the WWTP-A and $99.2 \%$ for the WWTP-B.

The total precipitation and each WWTP loading were analyzed, and the results were crossed with the levels of caffeine found in each month. It was observed that seasonal variation and effluent loadings affect the caffeine levels in most of the monitored months. However, some results did not follow the trend indicating possibility of illegal wastewater discharge into the river body. It is important to identify and eliminate the unknown pollution sources by the local authorities. This monitoring study proves that caffeine may be used as an indicator of anthropogenic pollution as this compound arises as emerging water pollutant. Based on the results, caffeine should be included to the water pollutant watch list as a key marker in the aquatic environment.

Funding information The authors received funding from the EU and FCT/UEFISCDI/FORMAS for funding, in the frame of the collaborative international consortium REWATER financed under the ERA-NET Cofund WaterWorks2015 Call. This ERA-NET is an integral part of the 2016 Joint Activities developed by the Water Challenges for a Changing World Joint Programme Initiative (Water JPI). This work was also supported by UID/QUI/50006/2019 with funding from FCT/MCTES through national funds.

\section{References}

2002/657/EC (2002) European Commission 2002/657/EC. Commission decision of 12 August 2002 implementing council directive 96/23/ EC concerning the performance of analytical methods and the interpretation of results (notified under document number C(2002) 3044, L221/8. Available at: http://faolex.fao.org/docs/pdf/eur49615.pdf. Accessed date: August 2017

Akcay H, Oguz A, Karapire C (2003) Study of heavy metal pollution and speciation in Buyak Menderes and Gediz river sediments. Water Res $37: 813-822$

Benotti MJ, Brownawell BJ (2007) Distributions of pharmaceuticals in an urban estuary during both dry- and wet-weather conditions. Environ Sci Technol 41:5795-5802

Boisvert M, Fayad P, Sauvé S (2012) Development of a new multi-residue laser diode thermal desorption atmospheric pressure chemical ionization tandem mass spectrometry method for the detection and quantification of pesticides and pharmaceuticals in wastewater samples. Anal Chim Acta 754:75-82

Buerge IJ, Poiger T, Muller MD, Buser H-R (2003) Caffeine, an anthropogenic marker for wastewater contamination of surface waters. Environ Sci Technol 37:691-700

ECOSAR Ecological Structure Activity Relationships (ECOSAR) (n.d.) Predictive Model

Edwards QA, Kulikov SM, Garner-O'Neale LD (2015) Caffeine in surface and wastewaters in Barbados, West Indies. SpringerPlus 4:57, $1-57,12$

EMEA (2006) Guideline on the environmental risk assessment of medicinal products for human use. European Medicines Agency PreAuthorisation Evaluation of Medicines for Human Use. London, 01 June 2006. Doc. Ref. EMEA/CHMP/SWP/4447/00 corr 2. Available at: http://www.ema.europa.eu/docs/en_GB/document library/Scientific guideline/2009/10/WC500003978.pdf. Accessed date: June 2017)

Fernández C, González-Doncel M, Pro J, Carbonell G, Tarazona JV (2010) Occurrence of pharmaceutically active compounds in surface waters of the Henares-Jarama-Tajo River system (Madrid, Spain) and a potential risk characterization. Sci Total Environ 408:543-551

Ferreira AP (2005) Caffeine as an environmental indicator for assessing urban aquatic ecosystems. Cad Saude Publica 21:1884-1892

Florescu D, Ionete RE, Sandru C, Iordache A, Culea M (2011) The influence of pollution monitoring parameters in characterizing the surface water quality from Romania southern area. Rom J Phys 56 : $1001-1010$

Glassmeyer ST, Furlong ET, Kolpin DW, Cahill JD, Zaugg SD, Werner SL, Meyer MT, Kryak DD (2005) Transport of chemical and microbial compounds from known wastewater discharges: potential for use as indicators of human fecal contamination. Environ Sci Technol 39:5157-5169

Heberer T (2002) Tracking persistent pharmaceutical residues from municipal sewage to drinking water. J Hydrol 266:175-189

Hillebrand O, Nödler K, Licha T, Sauter M, Geyer T (2012) Caffeine as an indicator for the quantification of untreated wastewater in karst systems. Water Res 46:395-402

Huerta-Fontela M, Galceran MT, Martin-Alonso J, Ventura F (2008) Occurrence of psychoactive stimulatory drugs in wastewaters in north-eastern Spain. Sci Total Environ 397:31-40 
Kiguchi O, Sato G, Kobayashi T (2016) Source-specific sewage pollution detection in urban river waters using pharmaceuticals and personal care products as molecular indicators. Environ Sci Pollut Res 23: 22513-22529

Kim S-C, Carlson K (2007) Quantification of human and veterinary antibiotics in water and sediment using SPE/LC/MS/MS. Anal Bioanal Chem 387:1301-1315

Kurissery S, Kanavillil N, Verenitch S, Mazumder A (2012) Caffeine as an anthropogenic marker of domestic waste: a study from Lake Simcoe watershed. Ecol Indic 23:501-508

LeiriaMunicipality (n.d.) Available http://www.cm-leiria.pt/. Accessed 14 Dec 2017

Loos R, Wollgast J, Huber T, Hanke G (2007) Polar herbicides, pharmaceutical products, perfluorooctanesulfonate (PFOS), perfluorooctanoate (PFOA), and nonylphenol and its carboxylates and ethoxylates in surface and tap waters around Lake Maggiore in Northern Italy. Anal Bioanal Chem 387:1469-1478

Mahoney CR, Giles GE, Marriott BP, Judelson DA, Glickman EL, Geiselman PJ, Lieberman HR, (2019) Intake of caffeine from all sources and reasons for use by college students. Clinical Nutrition 38 (2):668-675

Martín J, Camacho-Munoz D, Santos JL, Aparicio I, Alonso E (2012) Occurrence of pharmaceutical compounds in wastewater and sludge from wastewater treatment plants: removal and ecotoxicological impact of wastewater discharges and sludge disposal. J Hazard Mater 239-240:40-47

Nannou CI, Kosma CI, Albanis TA (2015) Occurrence of pharmaceuticals in surface waters: analytical method development and environmental risk assessment. Int J Environ Anal Chem 95:1242-1262

Paíga P, Santos LHMLM, Ramos S, Jorge S, Silva JG, Delerue-Matos C (2016) Presence of pharmaceuticals in the Lis river (Portugal): sources, fate and seasonal variation. Sci Total Environ 573:164-177

Paíga P, Santos LHMLM, Delerue-Matos C (2017) Development of a multi-residue method for the determination of human and veterinary pharmaceuticals and some of their metabolites in aqueous environmental matrices by SPE-UHPLC-MS/MS. J Pharm Biomed Anal 135:75-86

Panuwet P, Hunter REJ, D'Souza PE, Chen X, Radford SA, Cohen JR, Marder ME, Kartavenka K, Ryan PB, Barr DB (2016) Biological matrix effects in quantitative tandem mass spectrometry-based analytical methods: advancing biomonitoring. Crit Rev Anal Chem 46:93-105

Peteffi GP, Fleck JD, Kael IM, Girardi V, Bündchen R, Krajeski DM, Demoliner M, Silva FP, daRosa DC, Antunes MV, Linden R (2018) Caffeine levels as a predictor of Human mastadenovirus presence in surface waters-a case study in the Sinos River basin-Brazil. Environ Sci Pollut Res Int 25(16):15774-15784. https://doi.org/10.1007/ s11356-018-1649-3

R Development Core Team (2016) R: A Language and Environment for Statistical Computing. R Foundation for Statistical Computing, Vienna

Seiler RL, Zaugg SD, Thomas JM, Howcroft DL (1999) Caffeine and pharmaceuticals as indicators of wastewater contamination in wells. Ground Water 37:405-410

Siegener R, Chen RF (2002) Caffeine in Boston Harbor seawater. Mar Pollut Bull 44:383-387

Stamatis NK, Konstantinou IK (2013) Occurrence and removal of emerging pharmaceutical, personal care compounds and caffeine tracer in municipal sewage treatment plant in Western Greece. J Environ Sci Health B 48:800-813

Thomaidi VS, Stasinakis AS, Borova VL, Thomaidis NS (2015) Is there a risk for the aquatic environment due to the existence of emerging organic contaminants in treated domestic wastewater? Greece as a case-study. J Hazard Mater 283:740-747

Vazquez-Roig P, Andreu V, Blasco C, Picó Y (2012) Risk assessment on the presence of pharmaceuticals in sediments, soils and waters of the Pego-Oliva marshlands (Valencia, eastern Spain). Sci Total Environ 440:24-32

Vieira J, Fonseca A, Vilar VJP, Boaventura RAR, Botelho CMS (2012) Water quality in Lis river, Portugal. Environ Monit Assess 184: 7125-7140

Yang Y-Y, Liu W-R, Liu Y-S, Zhao J-L, Zhang Q-Q, Zhang M, Zhang JN, Jiang Y-X, Zhang L-J, Ying G-G (2017) Suitability of pharmaceuticals and personal care products (PPCPs) and artificial sweeteners (ASs) as wastewater indicators in the Pearl River Delta, South China. Sci Total Environ 590-591:611-619 